\title{
NiCu Bimetallic Nanoparticles on Silica Support for Catalytic Hydrolysis of Ammonia Borane: Composition-Dependent Activity and Support Size Effect
}

\author{
Kun Guo a,b, Yi Ding', Jun Luo ${ }^{c}$, Minfen $\mathrm{Gu}^{\mathrm{d}}$, and Zhixin $\mathrm{Yu}^{\mathrm{a}, *}$ \\ ${ }^{a}$ Department of Energy and Petroleum Engineering, University of Stavanger, 4036 Stavanger, Norway \\ ${ }^{b}$ School of Chemistry, University of Manchester, Oxford Road, M13 9PL Manchester, United Kingdom \\ ' Institute for New Energy Materials \& Low-Carbon Technologies, School of Materials Science and \\ Engineering, Tianjin University of Technology, Tianjin 300384, China \\ ${ }^{d}$ Center for Analysis and Testing, Nanjing Normal University, Nanjing 210046, China
}

${ }^{*}$ Corresponding authors:

Z.Yu: zhixin.yu@uis.no 


\section{Supporting Information}

\section{Table of Contents}

Note S1. Calculation method of the TOF 3

Table S1. Detailed amounts of the liquids used for preparing differently sizes $\mathrm{SiO}_{2}$ spheres. .4

Table S2. Average particle sizes and crystal sizes of the mono- and bi-metallic NPs measured from the TEM and XRD characterizations. .5

Table S3. Elemental contents in atomic percentage derived from the XPS and ICP-AES analysis............6

Table S4. Activation energy of the reported metal-based catalysts for the hydrolysis of AB.....................7

Table S5. TOF values of the reported metal-based catalysts for the hydrolysis of $\mathrm{AB}$.............................8

Figure S1. FTIR spectra of the $\mathrm{Ni}_{0.75} \mathrm{Cu}_{0.25} \mathrm{NPs}$, OAm, TOP, $\mathrm{Ni}(\mathrm{acac})_{2}$, and $\mathrm{Cu}(\mathrm{acac})_{2}$. The highlighted absorption bands at $\tilde{v}=2950 \sim 2850 \mathrm{~cm}^{-1}$ correspond to the $\mathrm{C}-\mathrm{H}$ stretches. .

Figure S2. Representative TEM images and the corresponding PSD curves of the $\mathrm{Ni}(\mathrm{a}, \mathrm{b}), \mathrm{Ni}_{0.75} \mathrm{Cu}_{0.25}(\mathrm{c}$, d), $\mathrm{Ni}_{0.5} \mathrm{Cu}_{0.5}(\mathrm{e}, \mathrm{f}), \mathrm{Ni}_{0.25} \mathrm{Cu}_{0.75}(\mathrm{~g}, \mathrm{~h})$ and $\mathrm{Cu}(\mathrm{i}, \mathrm{j}) \mathrm{NPs}$.

Figure S3. UV-Vis spectra of the mono- and bi-metallic NPs. .11

Figure S4. Reaction mechanism of the hydrolysis of $\mathrm{AB}$.

Figure S5. SEM images of the as-prepared $\mathrm{SiO}_{2}$ spheres with different APSs of (a) 47, (b) 97, (c) 195, (d) 333, (e) 391, and (f) $485 \mathrm{~nm}$. Scale bar is $2 \mu \mathrm{m}$.

Figure S6. XRD patterns of the as-prepared $\mathrm{SiO}_{2}$ spheres with different APSs.

Figure S7. FTIR spectra of the as-prepared $\mathrm{SiO}_{2}$ spheres with different APSs. The bands at $\tilde{v} \approx 474,802$, $953,1111,1400,1632$, and $3408 \mathrm{~cm}^{-1}$ are assigned to the vibrations of $\mathrm{Si}-\mathrm{O}-\mathrm{Si}, \mathrm{Si}-\mathrm{O}-\mathrm{Si}, \mathrm{Si}-\mathrm{OH}, \mathrm{Si}-\mathrm{O}-$ $\mathrm{Si}, \mathrm{C}-\mathrm{H}, \mathrm{O}-\mathrm{H}$, and $\mathrm{O}-\mathrm{H}$, respectively.

Figure S8. Nitrogen adsorption-desorption isotherms of the as-prepared $\mathrm{SiO}_{2}$ spheres with different APSs of (a) 47, (b) 97, (c) 195, (d) 333, (e) 391, and (f) $485 \mathrm{~nm}$.

Figure S9. XRD patterns of the as-prepared 47- $\mathrm{SiO}_{2}$ spheres, $\mathrm{Ni}_{0.75} \mathrm{Cu}_{0.25} \mathrm{NPs}$ and $\mathrm{Ni}_{0.75} \mathrm{Cu}_{0.25} / 47-\mathrm{SiO}_{2}$. 17 Figure S10. Representative TEM images of the $\mathrm{Ni}_{0.75} \mathrm{Cu}_{0.25} / 485-\mathrm{SiO}_{2}$ catalyst before (a) and after (b) the hydrolysis reaction.

Figure S11. Blank experiments of the hydrolysis of $\mathrm{AB}$ with six differently sized $\mathrm{SiO}_{2}$ for $2 \mathrm{~h}$.

Figure S12. TOFs of the unsupported $\mathrm{Ni}_{0.75} \mathrm{Cu}_{0.25} \mathrm{NPs}$ and supported $\mathrm{NiCu} / \mathrm{SiO}_{2}$ composites. .20

Figure S13. Simplified illustration of the migration process of NPs after the hydrolysis reaction for the $\mathrm{NiCu} / 47-\mathrm{SiO}_{2}$ and $\mathrm{NiCu} / 485-\mathrm{SiO}_{2}$.

References. 


\section{Supporting Information}

\section{Note S1. Calculation method of the TOF}

Considering that our mono- and bi-metallic NPs fall in a relatively large size domain, we calculate the TOF by assuming that only the metal atoms located in the outermost $5 \mathrm{~nm}$ layer of the highly dispersed NP are active in the liquid phase reaction system. ${ }^{1}$ The ratio $(R)$ of active metal atoms in each NP can be calculated as the equation below:

$$
R=1-\frac{\frac{4}{3} \pi\left(\frac{d_{M}-5}{2}\right)^{3}}{\frac{4}{3} \pi\left(\frac{d_{M}}{2}\right)^{3}}=1-\left(\frac{d_{M}-5^{3}}{d_{M}}\right)
$$

where $d_{M}$ is the diameter of metal NP. The calculation of TOF is thus given as the equation below:

$$
T O F=\frac{V_{H_{2}}}{22.4 * V_{S} * C_{M} * t * R}
$$

where $V_{H_{2}}$ is the total volume of $\mathrm{H}_{2}$ generated, $V_{S}$ is the volume of solution, $C_{M}$ is the molar concentration of metal NPs added in the reaction mixture, and $t$ is the reaction time..$^{2-4}$ 


\section{Supporting Information}

Table S1. Amounts of the liquids used for preparing differently-sized $\mathrm{SiO}_{2}$ spheres.

\begin{tabular}{|c|c|c|c|c|c|}
\hline \multicolumn{3}{|c|}{ Solution $A^{a}$} & \multicolumn{2}{|c|}{ Solution $\mathbf{B}^{b}$} & \multirow{2}{*}{$\mathrm{SiO}_{2} \mathrm{APS}^{c}$} \\
\hline Ammonia & DI Water & Ethanol & TEOS & Ethanol & \\
\hline $2.0 \mathrm{~mL}$ & 0 & $48.0 \mathrm{~mL}$ & \multirow{6}{*}{$5.0 \mathrm{~mL}$} & \multirow{6}{*}{$45.0 \mathrm{~mL}$} & $47 \mathrm{~nm}$ \\
\hline $3.0 \mathrm{~mL}$ & $1.5 \mathrm{~mL}$ & $45.5 \mathrm{~mL}$ & & & $97 \mathrm{~nm}$ \\
\hline $3.0 \mathrm{~mL}$ & $3.0 \mathrm{~mL}$ & $44.0 \mathrm{~mL}$ & & & $195 \mathrm{~nm}$ \\
\hline $4.0 \mathrm{~mL}$ & $4.0 \mathrm{~mL}$ & $42.0 \mathrm{~mL}$ & & & $333 \mathrm{~nm}$ \\
\hline $10.0 \mathrm{~mL}$ & $25.0 \mathrm{~mL}$ & $15.0 \mathrm{~mL}$ & & & $391 \mathrm{~nm}$ \\
\hline $8.0 \mathrm{~mL}$ & $10.0 \mathrm{~mL}$ & $32.0 \mathrm{~mL}$ & & & $485 \mathrm{~nm}$ \\
\hline
\end{tabular}

${ }^{a}$ The initial solution in the beaker.

${ }^{b}$ The solution added to the beaker.

${ }^{c}$ APS=average particle size. 


\section{Supporting Information}

Table S2. Average particle sizes and crystal sizes of the mono- and bi-metallic NPs measured from the TEM and XRD characterizations.

\begin{tabular}{ccc}
\hline Samples & $\begin{array}{c}\text { Average particle size from } \\
\mathbf{T E M}(\mathbf{n m})\end{array}$ & $\begin{array}{c}\text { Average crystal size from } \\
\mathbf{X R D}^{\boldsymbol{a}}(\mathbf{n m})\end{array}$ \\
\hline $\mathbf{N i}$ & 10.0 & 3.9 \\
$\mathbf{N i}_{\mathbf{0 . 5}} \mathbf{C} \mathbf{u}_{\mathbf{0 . 2 5}}$ & 9.9 & 6.4 \\
$\mathbf{N i}_{\mathbf{0 . 5}} \mathbf{C} \mathbf{u}_{\mathbf{0 . 5}}$ & 13.5 & 8.3 \\
$\mathbf{N i}_{\mathbf{0 . 5}} \mathbf{C} \mathbf{u}_{\mathbf{0 . 7 5}}$ & 11.8 & 9.1 \\
$\mathbf{C u}$ & 19.7 & 15.8 \\
\hline
\end{tabular}

${ }^{a}$ Calculation based on the (111) crystal plane using the Scherrer equation. 


\section{Supporting Information}

Table S3. Elemental contents in atomic percentage derived from the XPS and ICP-AES analysis.

\begin{tabular}{ccccc}
\hline & \multicolumn{4}{c}{ Elemental content (atom \%) } \\
\cline { 2 - 5 } Samples & $\mathbf{N i}^{a}$ & $\mathbf{C} \mathbf{u}^{a}$ & $\mathbf{N i}^{b}$ & $\mathbf{C u}^{b}$ \\
$\mathbf{N i}_{\mathbf{0 . 7 5}} \mathbf{C u}_{\mathbf{0 . 2 5}}$ & 70.1 & 29.9 & 76.8 & 23.2 \\
$\mathbf{N i}_{\mathbf{0 . 5}} \mathbf{C u}_{\mathbf{0 . 5}}$ & 48.4 & 51.6 & 47.7 & 52.3 \\
$\mathbf{N i}_{\mathbf{0 . 2 5}} \mathbf{C u}_{\mathbf{0 . 7 5}}$ & 23.1 & 76.9 & 24.2 & 75.8 \\
\hline${ }^{a}$ XPS data. & & & \\
${ }^{b}$ ICP-AES data. & & & &
\end{tabular}




\section{Supporting Information}

Table S4. Activation energy of the reported metal-based catalysts for the hydrolysis of AB.

\begin{tabular}{|c|c|c|}
\hline Catalyst & Activation Energy $\left(\mathrm{kJ} \cdot \mathrm{mol}^{-1}\right)$ & Reference \\
\hline $\mathrm{Ni}_{0.75} \mathrm{Cu}_{0.25}$ & 34.2 & this study \\
\hline $3.2 \mathrm{~nm} \mathrm{Ni} / \mathrm{KB}$ & 28 & 5 \\
\hline $8.9 \mathrm{~nm}$ Ni NPs & 66.6 & 6 \\
\hline Pd/zeolite & 55.9 & 7 \\
\hline Pd/hydroxyapatite & 54.8 & 8 \\
\hline $\mathrm{Cu}_{0.2} @ \mathrm{Co}_{0.8} /$ graphene & 51.3 & 9 \\
\hline $\mathrm{Cu}_{0.4} @ \mathrm{Fe}_{0.1} \mathrm{Ni}_{0.5}$ & 32.9 & 10 \\
\hline $\mathrm{Ag} / \mathrm{C} / \mathrm{Ni}$ & 38.9 & 11 \\
\hline $\mathbf{R} \mathbf{u}_{1} \mathrm{Cu} \mathbf{u}_{7.5} /$ graphene & 30.6 & 12 \\
\hline Co/zeolite & 56 & 13 \\
\hline Cu/zeolite & 51.8 & 14 \\
\hline Co/PEI-GO & 28.2 & 15 \\
\hline $\mathrm{Ni} / \mathrm{Al}_{2} \mathrm{O}_{3}$ & 34 & 16 \\
\hline $\mathrm{Cu} @ \mathrm{SiO}_{2}$ & 36 & 17 \\
\hline PEG stabilized Fe & 37.0 & 18 \\
\hline Co@N-C-700 & 31.0 & 19 \\
\hline $\mathrm{NiAgPd} / \mathrm{C}$ & 38.4 & 20 \\
\hline $\mathbf{N i}_{30} \mathbf{P d}_{70} / \mathbf{r G O}$ & 45.0 & 21 \\
\hline $\mathrm{Cu}_{75} \mathbf{P d}_{25} / \mathrm{rGO}$ & 45.0 & 22 \\
\hline
\end{tabular}




\section{Supporting Information}

Table S5. TOFs of the reported metal-based catalysts for the hydrolysis of AB.

\begin{tabular}{|c|c|c|}
\hline Catalyst & 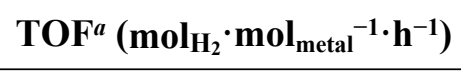 & Reference \\
\hline $\mathrm{Ni}_{0.75} \mathrm{Cu}_{0.25} / 47-\mathrm{SiO}_{2}$ & 1516 & this study \\
\hline $3.2 \mathrm{~nm} \mathrm{Ni} / \mathrm{KB}$ & 528 & 5 \\
\hline $\mathrm{Ni} @$ meso-SiO 2 & 1110 & 23 \\
\hline Ni/ZIF-8 & 852 & 24 \\
\hline PEG stabilized Fe & 384 & 18 \\
\hline Co/zeolite & 322 & 13 \\
\hline Co/graphene & 834 & 25 \\
\hline Pd/zeolite & 375 & 7 \\
\hline $\mathrm{Pd} / \mathrm{CeO}_{2}$ & 1740 & 26 \\
\hline Metastable Ru NPs & 1308 & 27 \\
\hline Ag@Ni/graphene & 462 & 28 \\
\hline Cu@Co/graphene & 502 & 9 \\
\hline $\mathrm{Cu} @ \mathrm{FeNi}$ & 502 & 10 \\
\hline $\mathrm{Ag} / \mathrm{C} / \mathrm{Ni}$ & 319 & 11 \\
\hline CuCo/graphene & 589 & 29 \\
\hline $\mathbf{R u}_{1} \mathbf{C} \mathbf{u}_{7.5} /$ graphene & 588 & 12 \\
\hline $\mathbf{N i}_{30} \mathbf{P d} d_{70} / \mathbf{r G O}$ & 1698 & 21 \\
\hline $\mathrm{PtNi} @ \mathrm{SiO}_{2}$ & 332 & 30 \\
\hline CoNi/graphene & 809 & 31 \\
\hline Au@Co & 816 & 32 \\
\hline $\mathrm{SnPd} / \mathrm{C}$ & 818 & 33 \\
\hline CoNi/rGO & 1172 & 34 \\
\hline CuCo@MIL-101 & 1176 & 35 \\
\hline AuCo@MIL-101 & 1410 & 36 \\
\hline
\end{tabular}

${ }^{a}$ Values either recalculated or directly collected from the data in the original studies. 
Supporting Information

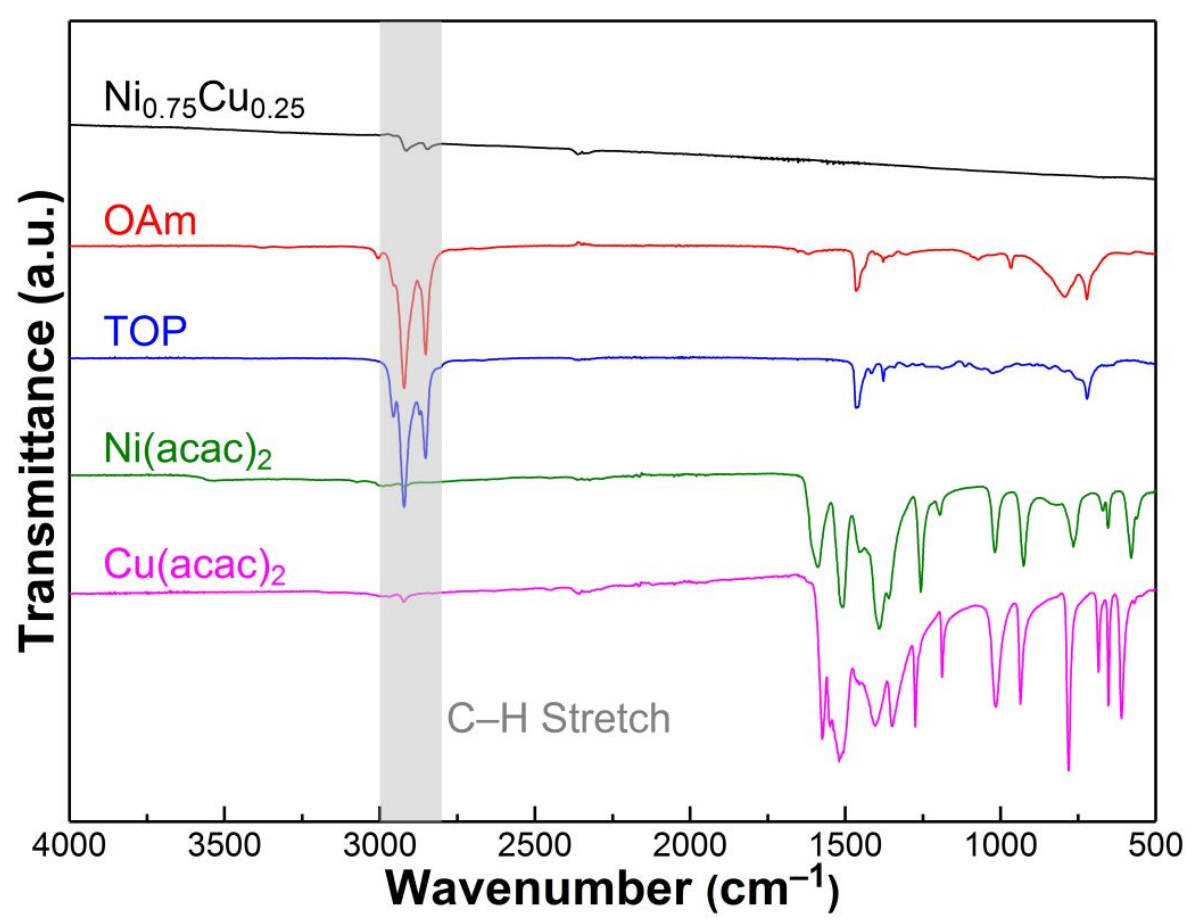

Figure S1. FTIR spectra of the $\mathrm{Ni}_{0.75} \mathrm{Cu}_{0.25} \mathrm{NPs}, \mathrm{OAm}, \mathrm{TOP}, \mathrm{Ni}(\mathrm{acac})_{2}$, and $\mathrm{Cu}(\mathrm{acac})_{2}$. The highlighted absorption bands at $\tilde{v}=2950 \sim 2850 \mathrm{~cm}^{-1}$ correspond to the $\mathrm{C}-\mathrm{H}$ stretches. 
Supporting Information

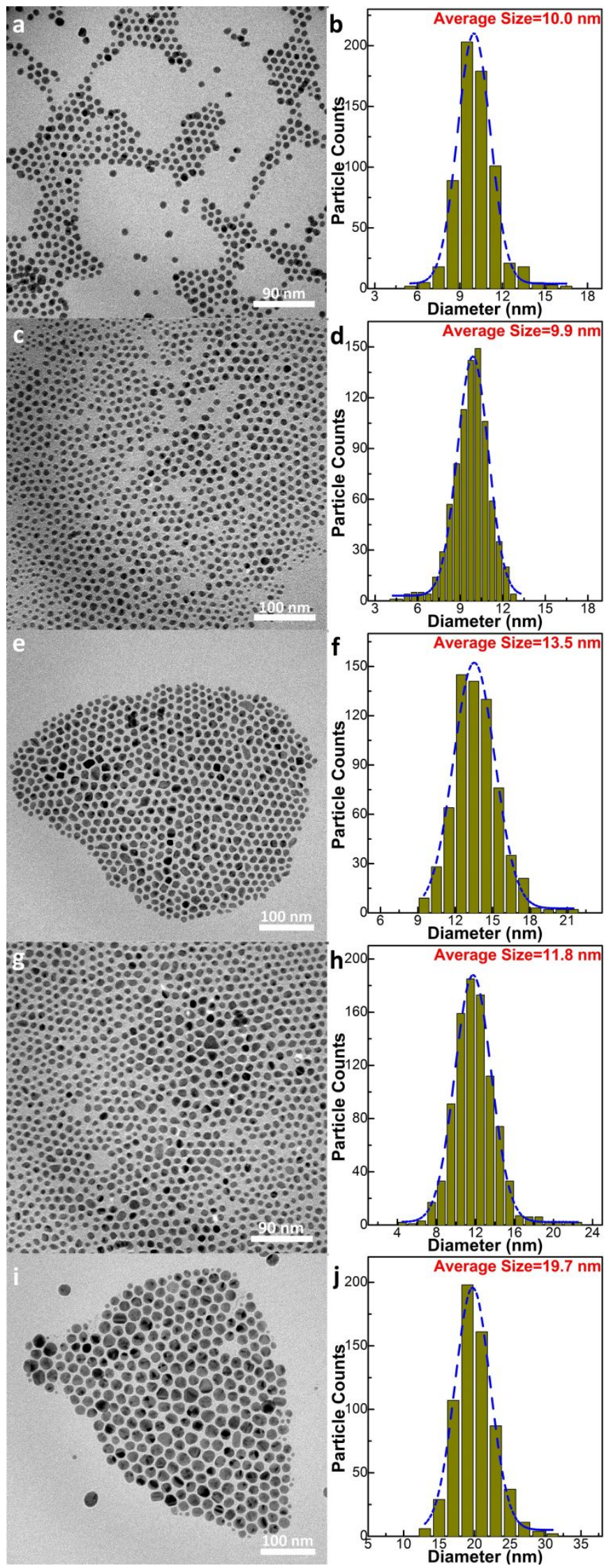

Figure S2. Representative TEM images and the corresponding PSD curves of the $\mathrm{Ni}(\mathrm{a}, \mathrm{b}), \mathrm{Ni}_{0.75} \mathrm{Cu}_{0.25}(\mathrm{c}$, d), $\mathrm{Ni}_{0.5} \mathrm{Cu}_{0.5}(\mathrm{e}, \mathrm{f}), \mathrm{Ni}_{0.25} \mathrm{Cu}_{0.75}(\mathrm{~g}, \mathrm{~h})$ and $\mathrm{Cu}(\mathrm{i}, \mathrm{j}) \mathrm{NPs}$. 
Supporting Information

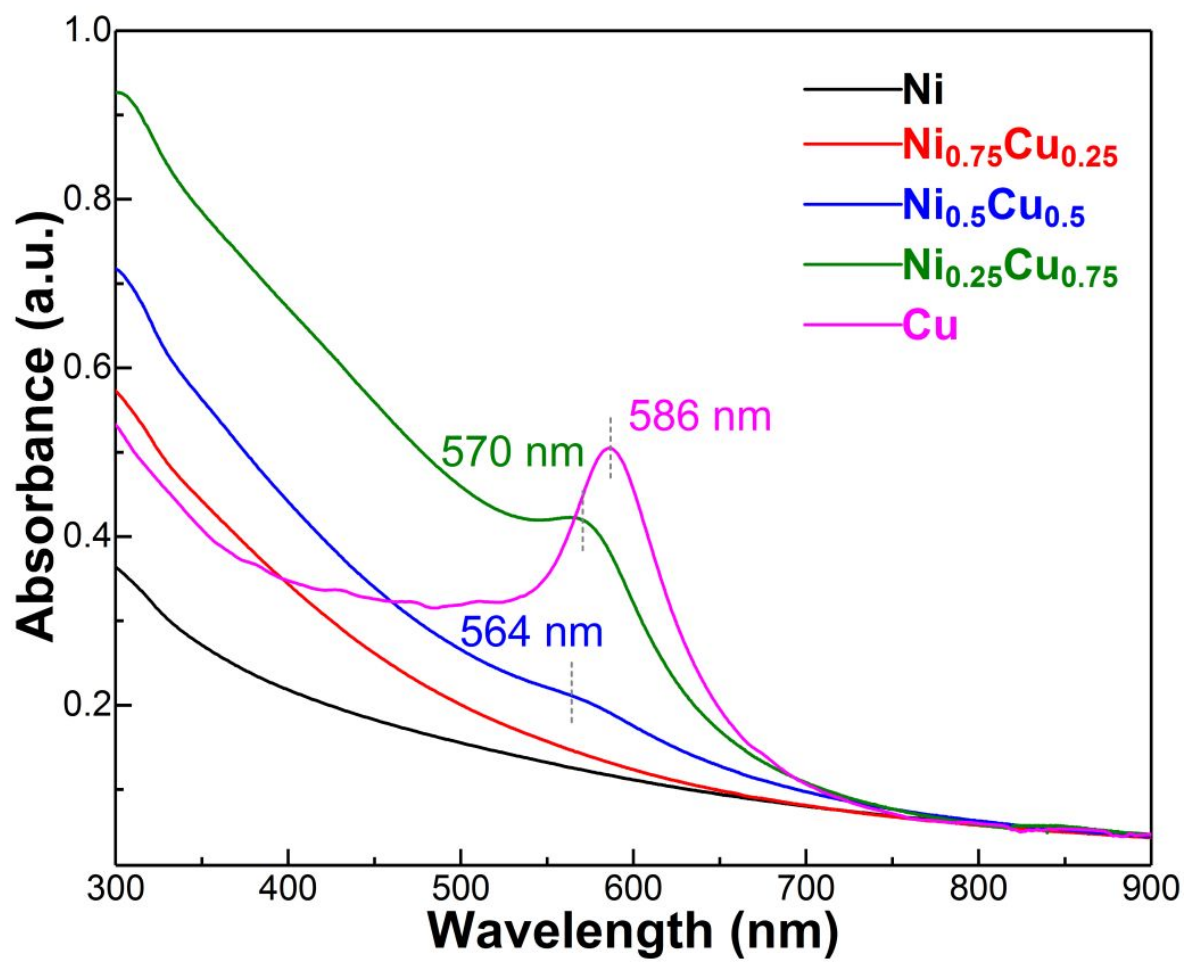

Figure S3. UV-Vis spectra of the mono- and bi-metallic NPs. 


\section{Supporting Information}

$\begin{array}{lllllllllllll}\mathrm{H}_{3} \mathrm{~N}-\mathrm{BH}_{3} & -\mathrm{NH}_{3} & \mathrm{H}_{2} \mathrm{O} & -\mathrm{NH}_{3} & \mathrm{H}_{2} \mathrm{O} & -\mathrm{NH}_{3} & \mathrm{H}_{2} \mathrm{O} & -\mathrm{NH}_{3} & & -\mathrm{NH}_{4}^{+} \\ & -\mathrm{BH}_{3} & \mathrm{H}_{2} & -\mathrm{OH} & -\mathrm{BH}_{2} & \mathrm{H}_{2} & -\mathrm{OH} & -\mathrm{OH}) & \mathrm{H}_{2} & -\mathrm{OH}(\mathrm{OH})_{2} & \mathrm{H}_{2} \mathrm{O} & -\mathrm{BO}_{2}^{-}\end{array}$

Figure S4. Reaction mechanism of the hydrolysis of AB. 
Supporting Information

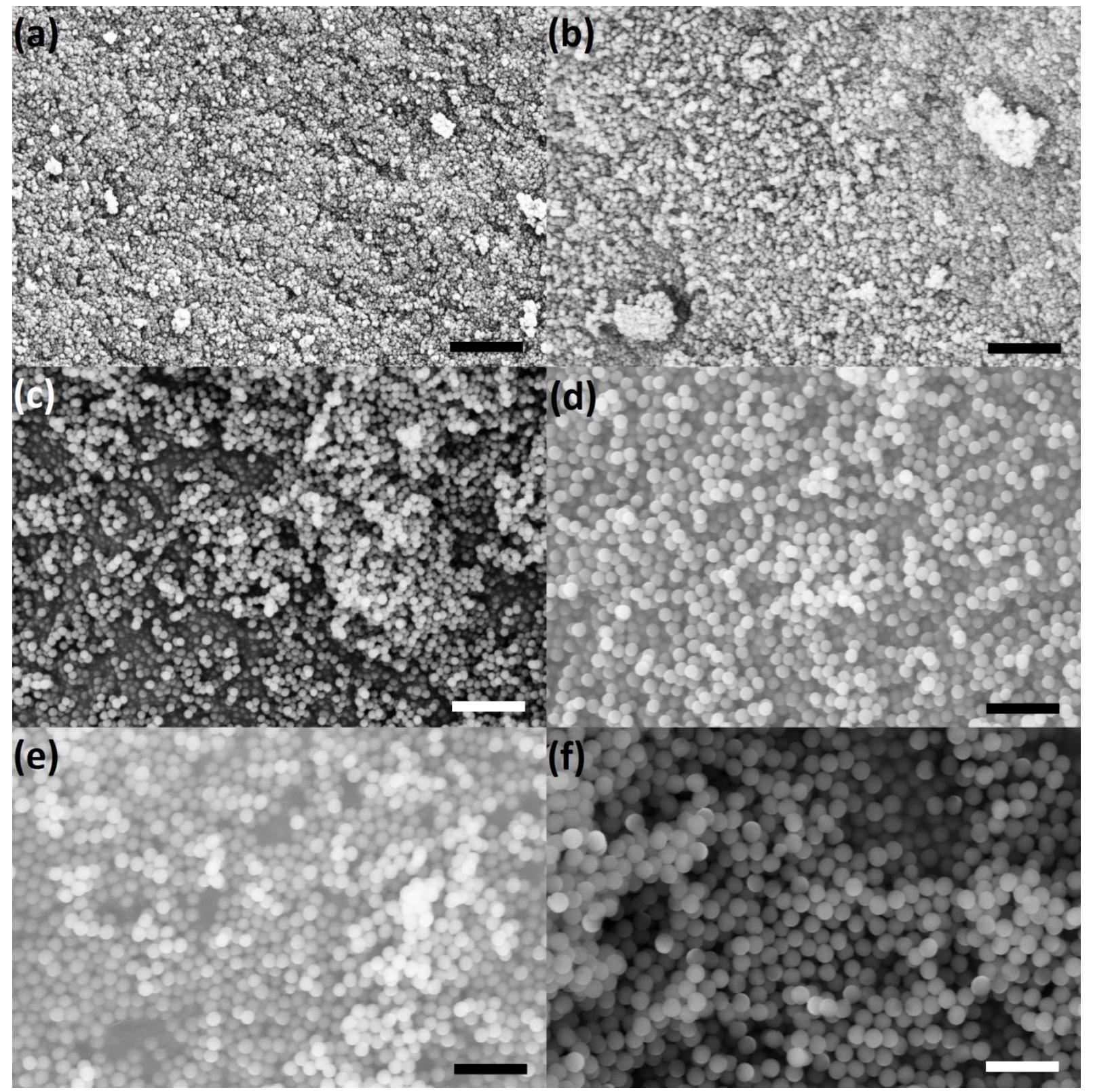

Figure S5. SEM images of the as-prepared $\mathrm{SiO}_{2}$ spheres with different APSs of (a) 47, (b) 97, (c) 195, (d) 333, (e) 391 , and (f) $485 \mathrm{~nm}$. Scale bar is $2 \mu \mathrm{m}$. 
Supporting Information

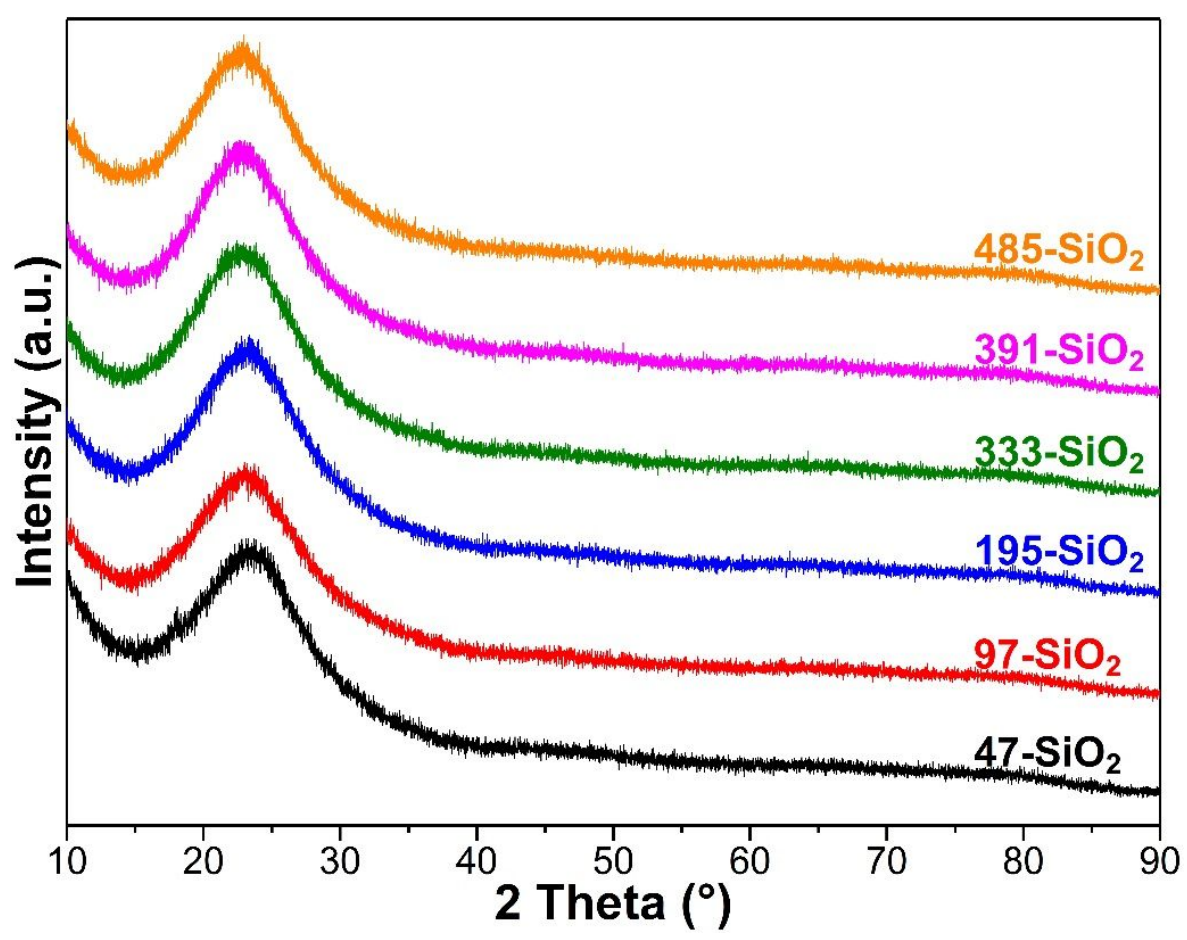

Figure S6. XRD patterns of the as-prepared $\mathrm{SiO}_{2}$ spheres with different APSs. 
Supporting Information

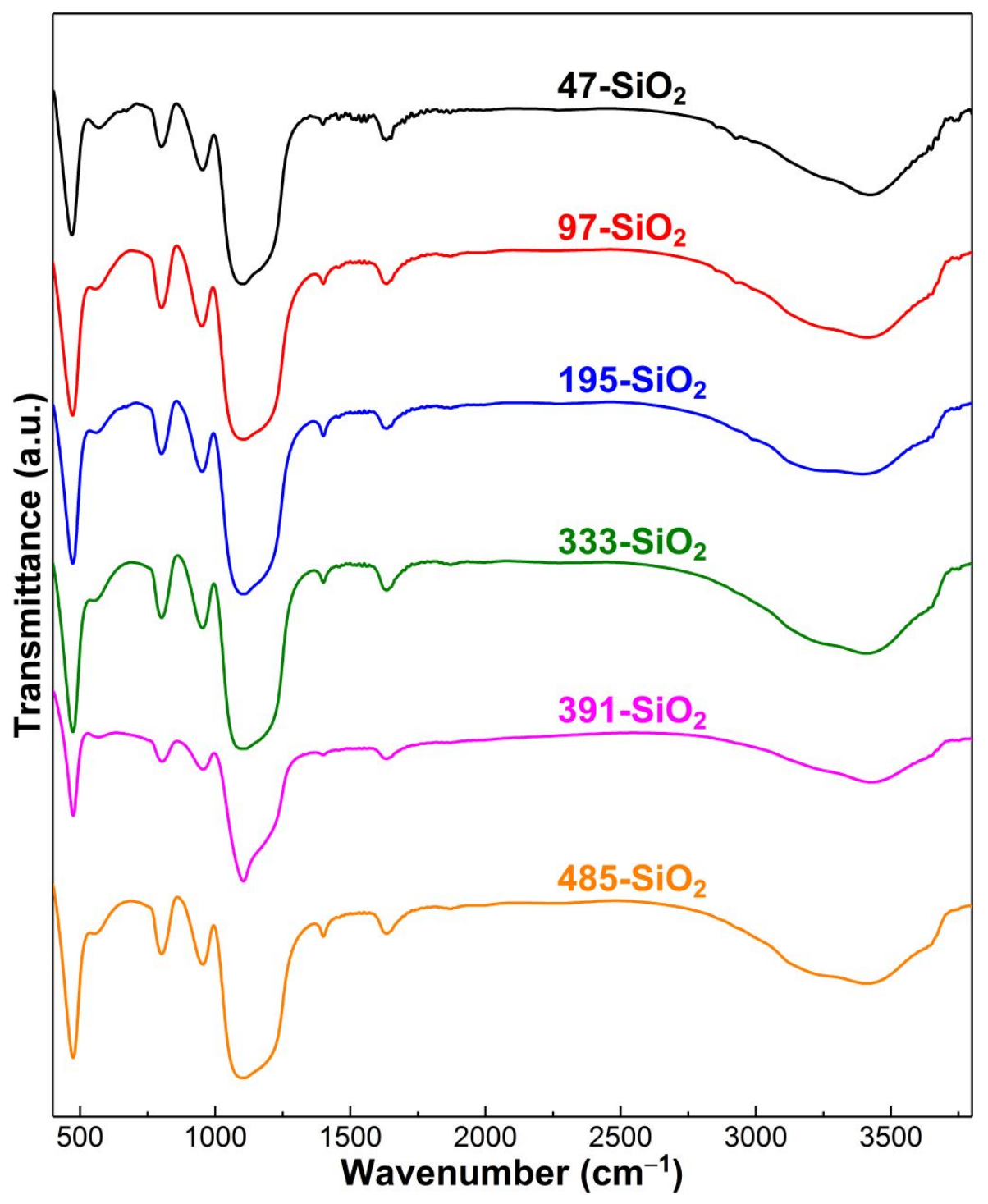

Figure S7. FTIR spectra of the as-prepared $\mathrm{SiO}_{2}$ spheres with different APSs. The bands at $\tilde{v} \approx 474,802$, $953,1111,1400,1632$, and $3408 \mathrm{~cm}^{-1}$ are assigned to the vibrations of $\mathrm{Si}-\mathrm{O}-\mathrm{Si}, \mathrm{Si}-\mathrm{O}-\mathrm{Si}, \mathrm{Si}-\mathrm{OH}, \mathrm{Si}-\mathrm{O}-$ $\mathrm{Si}, \mathrm{C}-\mathrm{H}, \mathrm{O}-\mathrm{H}$, and $\mathrm{O}-\mathrm{H}$, respectively. 
Supporting Information
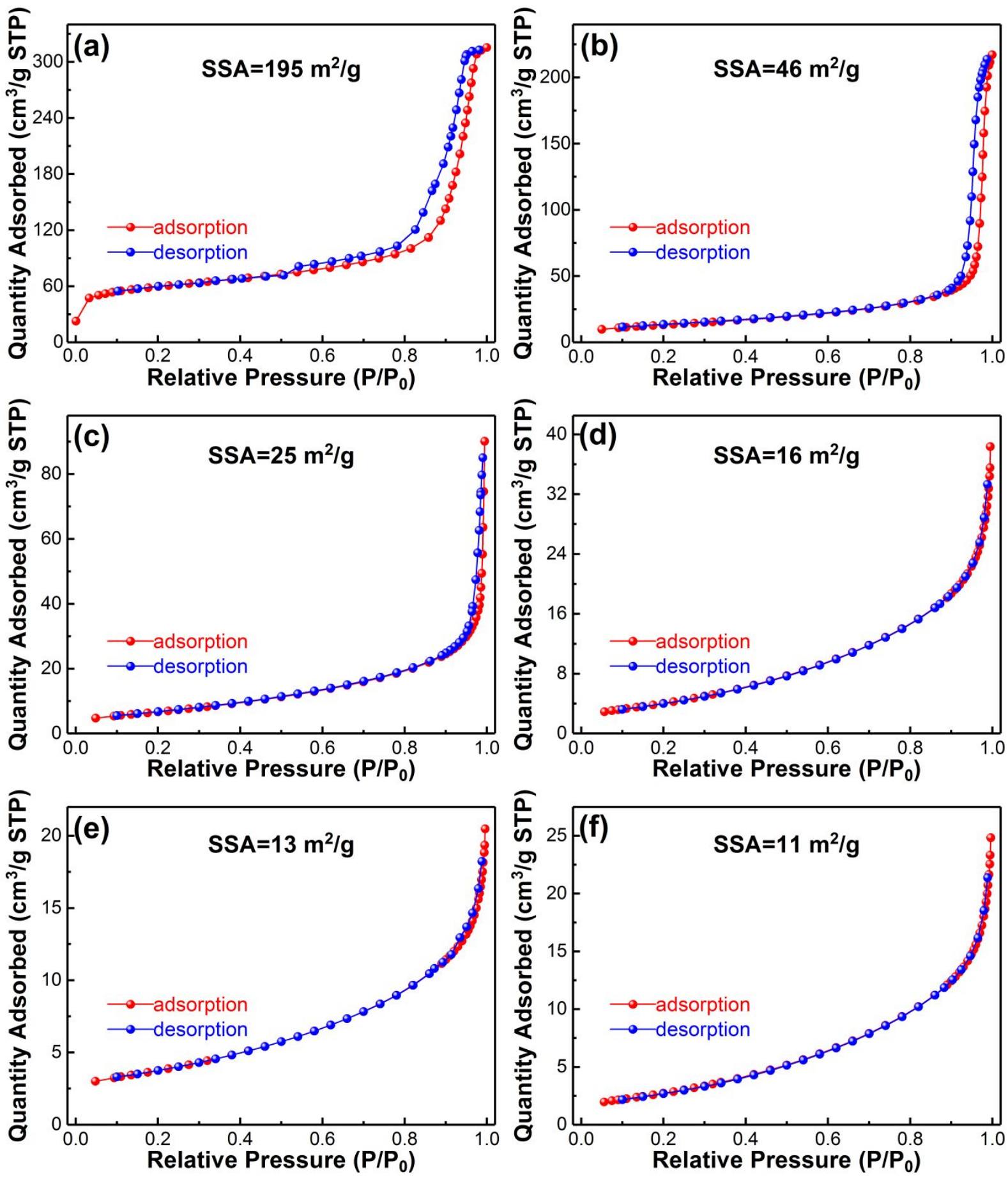

Figure S8. Nitrogen adsorption-desorption isotherms of the as-prepared $\mathrm{SiO}_{2}$ spheres with different APSs of (a) 47, (b) 97, (c) 195, (d) 333, (e) 391, and (f) $485 \mathrm{~nm}$. 
Supporting Information

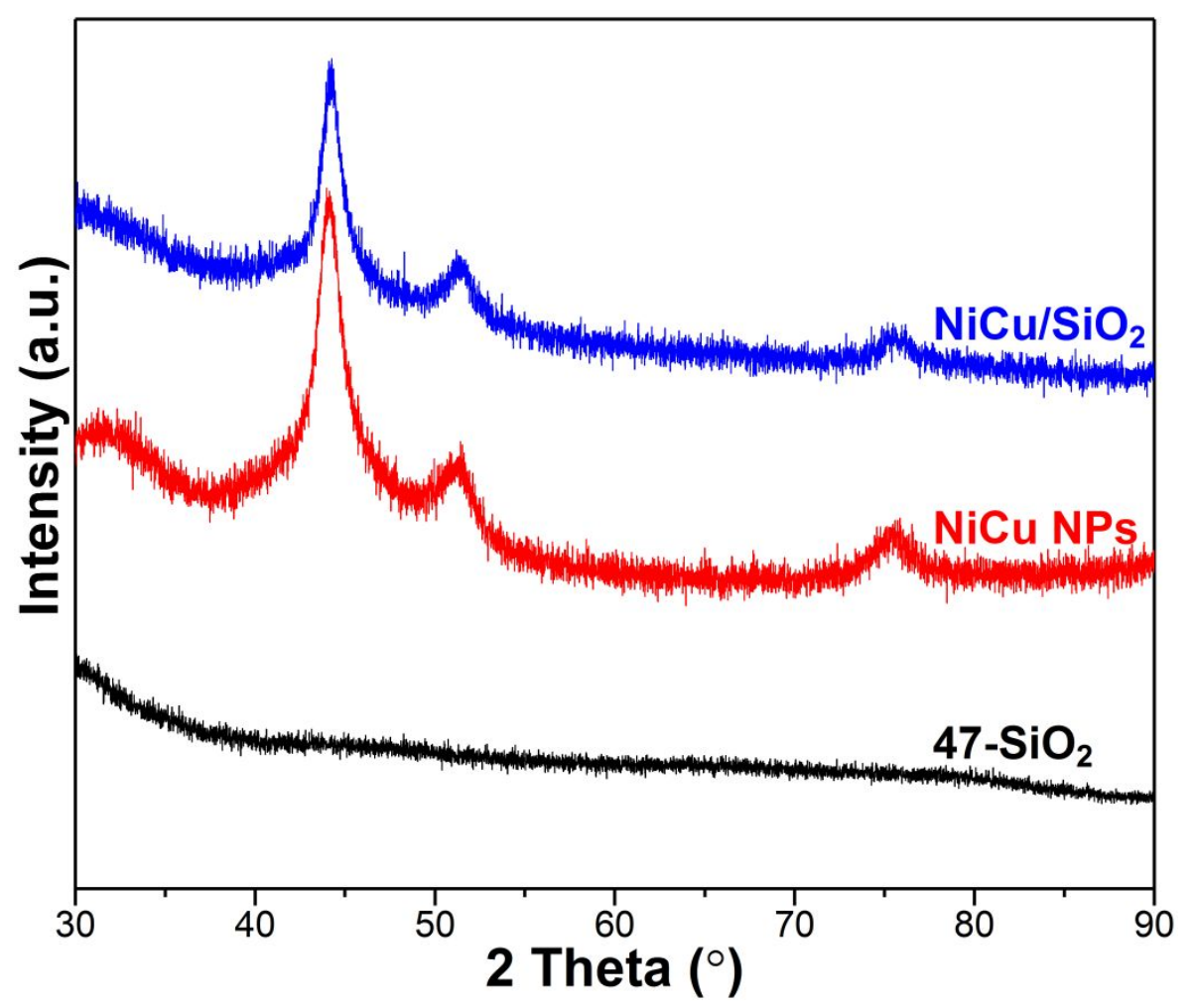

Figure S9. XRD patterns of the as-prepared 47- $\mathrm{SiO}_{2}$ spheres, $\mathrm{Ni}_{0.75} \mathrm{Cu}_{0.25} \mathrm{NPs}$ and $\mathrm{Ni}_{0.75} \mathrm{Cu}_{0.25} / 47-\mathrm{SiO}_{2}$. 


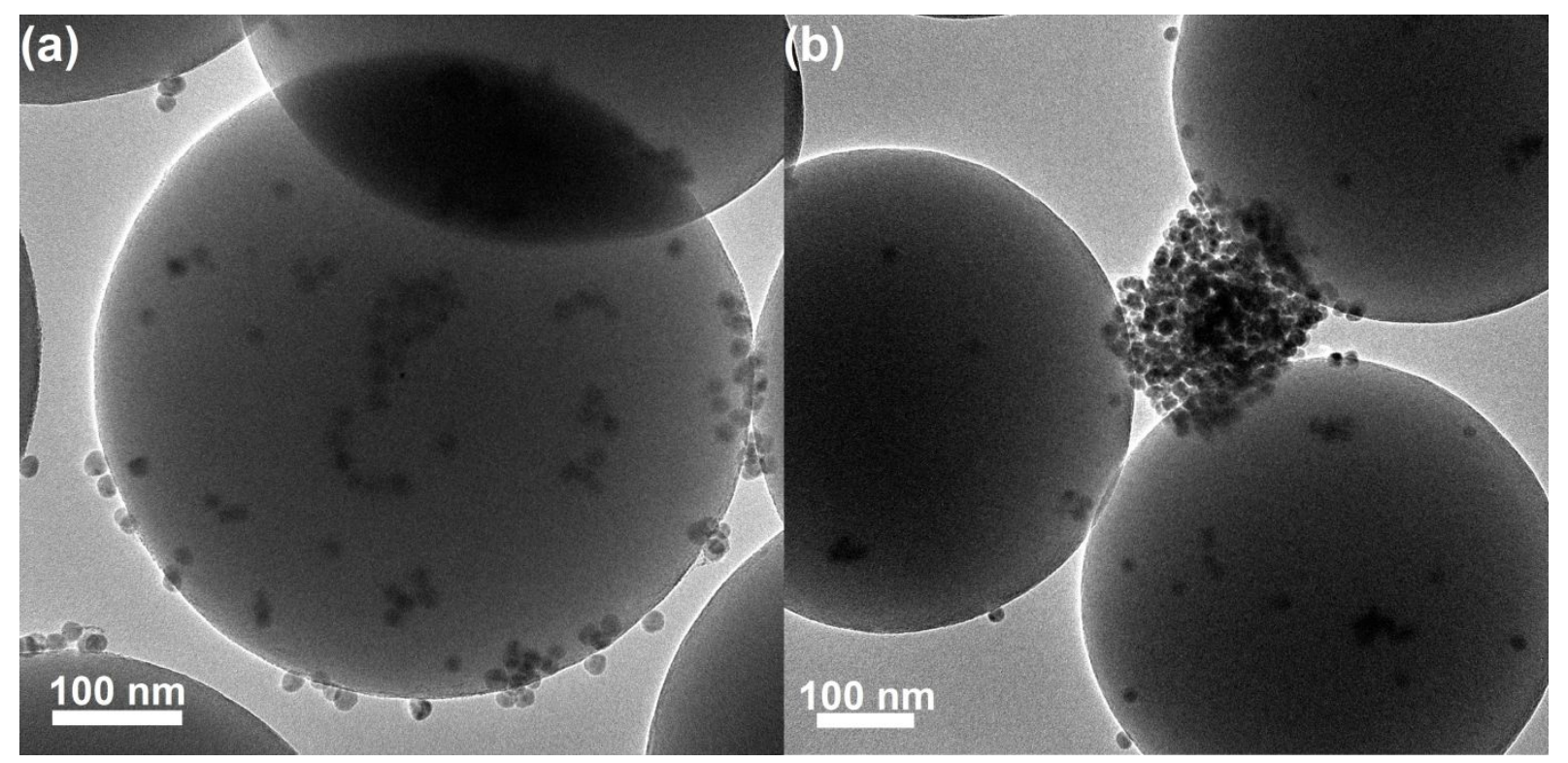

Figure S10. Representative TEM images of the $\mathrm{Ni}_{0.75} \mathrm{Cu}_{0.25} / 485-\mathrm{SiO}_{2}$ catalyst before (a) and after (b) the hydrolysis reaction. 
Supporting Information

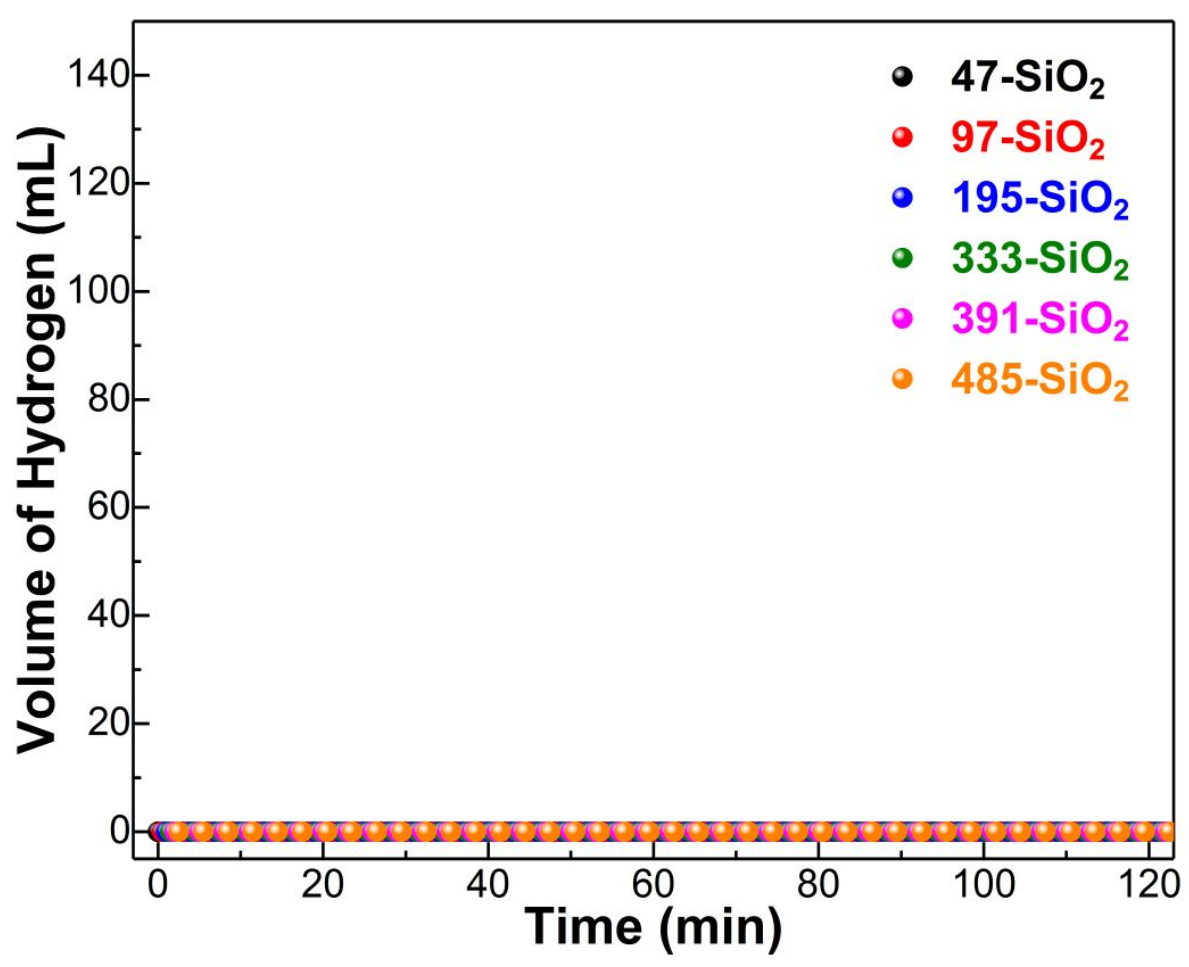

Figure S11. Blank experiments of the hydrolysis of $\mathrm{AB}$ with six differently sized $\mathrm{SiO}_{2}$ for $2 \mathrm{~h}$. 
Supporting Information

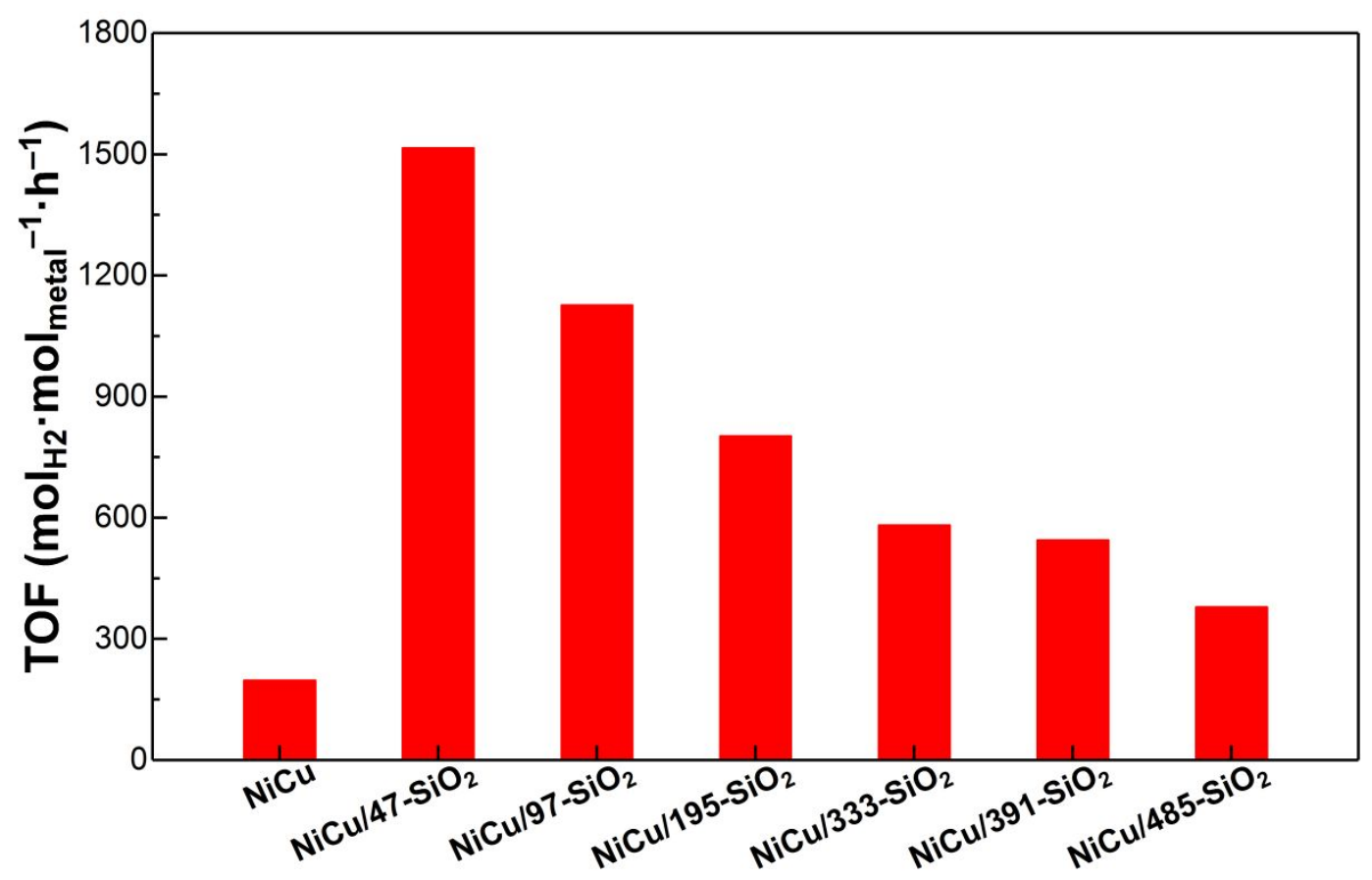

Figure S12. TOFs of the unsupported $\mathrm{Ni}_{0.75} \mathrm{Cu}_{0.25} \mathrm{NPs}$ and supported $\mathrm{NiCu} / \mathrm{SiO}_{2}$ composites. 
Supporting Information
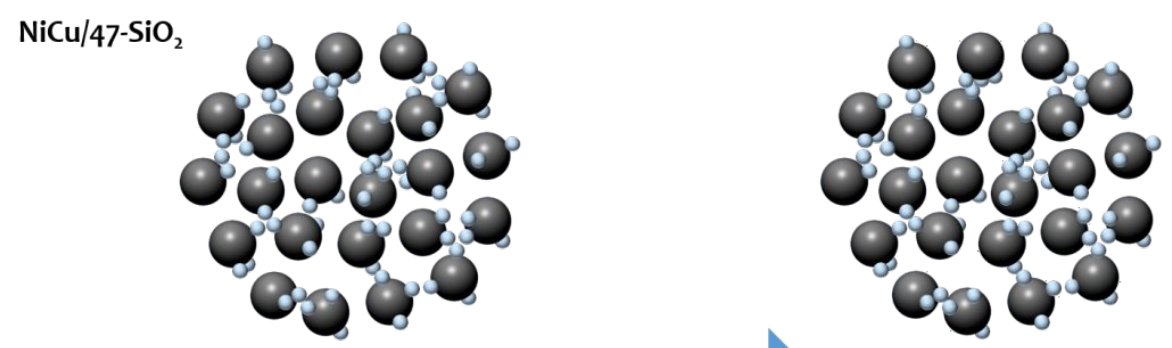

\section{After reaction}
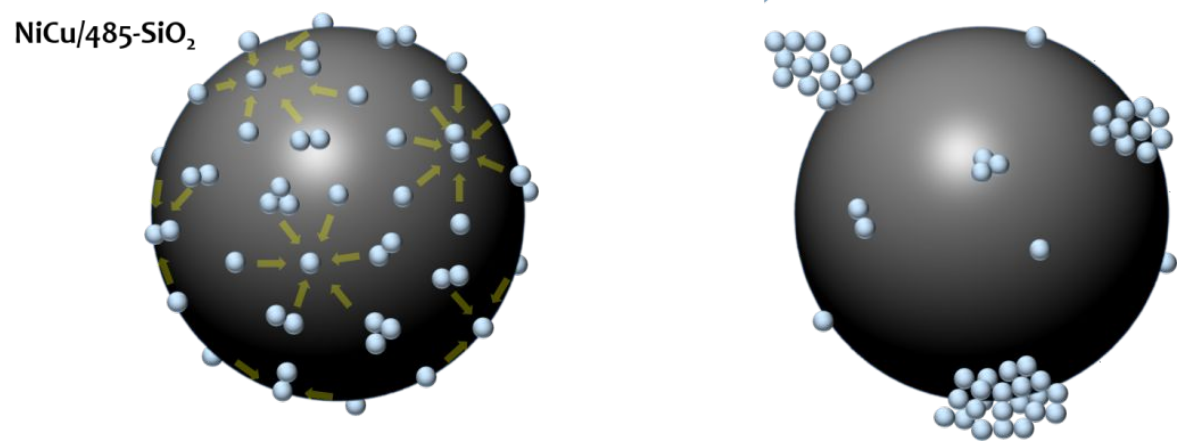

Figure S13. Simplified illustration of the migration process of NPs after the hydrolysis reaction for the $\mathrm{NiCu} / 47-\mathrm{SiO}_{2}$ and $\mathrm{NiCu} / 485-\mathrm{SiO}_{2}$. 


\section{Supporting Information}

\section{References}

(1) Guo, L. L.; Gu, X. J.; Kang, K.; Wu, Y. Y.; Cheng, J.; Liu, P. L.; Wang, T. S.; Su, H. Q. Porous NitrogenDoped Carbon-Immobilized Bimetallic Nanoparticles as Highly Efficient Catalysts for Hydrogen Generation from Hydrolysis of Ammonia Borane. J. Mater. Chem. A 2015, 3, 22807-22815.

(2) Yao, Q. L.; Lu, Z. H.; Huang, W.; Chen, X. S.; Zhu, J. High Pt-Like Activity of the Ni-Mo/Graphene Catalyst for Hydrogen Evolution from Hydrolysis of Ammonia Borane. J. Mater. Chem. A 2016, 4, 8579-8583.

(3) Liu, P.; Gu, X.; Kang, K.; Zhang, H.; Cheng, J.; Su, H. Highly Efficient Catalytic Hydrogen Evolution from Ammonia Borane Using the Synergistic Effect of Crystallinity and Size of Noble-Metal-Free Nanoparticles Supported by Porous Metal-Organic Frameworks. ACS Appl. Mater. Interfaces 2017, 9, 10759-10767.

(4) Ge, Y.; Ye, W.; Shah, Z. H.; Lin, X.; Lu, R.; Zhang, S. PtNi/NiO Clusters Coated by Hollow Sillica: Novel Design for Highly Efficient Hydrogen Production from Ammonia-Borane. ACS Appl. Mater. Interfaces 2017, 9, 3749-3756.

(5) Metin, O.; Mazumder, V.; Ozkar, S.; Sun, S. Monodisperse Nickel Nanoparticles and Their Catalysis in Hydrolytic Dehydrogenation of Ammonia Borane. J. Am. Chem. Soc. 2010, 132, 1468-1469.

(6) Guo, K.; Li, H.; Yu, Z. Size-Dependent Catalytic Activity of Monodispersed Nickel Nanoparticles for the Hydrolytic Dehydrogenation of Ammonia Borane. ACS Appl. Mater. Interfaces 2018, 10, $517-525$.

(7) Rakap, M.; Ozkar, S. Zeolite Confined Palladium(0) Nanoclusters as Effective and Reusable Catalyst for Hydrogen Generation from the Hydrolysis of Ammonia-Borane. Int. J. Hydrogen Energy 2010, 35, 1305-1312.

(8) Rakap, M.; Ozkar, S. Hydroxyapatite-Supported Palladium(0) Nanoclusters as Effective and Reusable Catalyst for Hydrogen Generation from the Hydrolysis of Ammonia-Borane. Int. J. Hydrogen Energy 2011, $36,7019-7027$.

(9) Du, Y. S.; Cao, N.; Yang, L.; Luo, W.; Cheng, G. Z. One-Step Synthesis of Magnetically Recyclable Rgo Supported Cu@Co Core-Shell Nanoparticles: Highly Efficient Catalysts for Hydrolytic Dehydrogenation of Ammonia Borane and Methylamine Borane. New J. Chem. 2013, 37, 3035-3042.

(10) Wang, H. L.; Yan, J. M.; Wang, Z. L.; Jiang, Q. One-Step Synthesis of Cu@FeNi Core-Shell Nanoparticles: Highly Active Catalyst for Hydrolytic Dehydrogenation of Ammonia Borane. Int. J. Hydrogen Energy 2012, 37, 10229-10235.

(11) Wen, M.; Sun, B. L.; Zhou, B.; Wu, Q. S.; Peng, J. Controllable Assembly of Ag/C/Ni Magnetic Nanocables and Its Low Activation Energy Dehydrogenation Catalysis. J. Mater. Chem. 2012, 22, $11988-11993$.

(12) Cao, N.; Hu, K.; Luo, W.; Cheng, G. Z. RuCu Nanoparticles Supported on Graphene: A Highly Efficient Catalyst for Hydrolysis of Ammonia Borane. J. Alloys Compd. 2014, 590, 241-246.

(13) Rakap, M.; Ozkar, S. Hydrogen Generation from the Hydrolysis of Ammonia-Borane Using Intrazeolite Cobalt(0) Nanoclusters Catalyst. Int. J. Hydrogen Energy 2010, 35, 3341-3346.

(14) Zahmakıran, M.; Durap, F.; Özkar, S. Zeolite Confined Copper(0) Nanoclusters as Cost-Effective and Reusable Catalyst in Hydrogen Generation from the Hydrolysis of Ammonia-Borane. Int. J. Hydrogen Energy 2010, 35, 187-197.

(15) Hu, J.; Chen, Z.; Li, M.; Zhou, X.; Lu, H. Amine-Capped Co Nanoparticles for Highly Efficient Dehydrogenation of Ammonia Borane. ACS Appl. Mater. Interfaces 2014, 6, 13191-13200.

(16) Metin, O.; Ozkar, S.; Sun, S. H. Monodisperse Nickel Nanoparticles Supported on $\mathrm{SiO}_{2}$ as an Effective Catalyst for the Hydrolysis of Ammonia-Borane. Nano Res. 2010, 3, 676-684.

(17) Yao, Q.; Lu, Z. H.; Zhang, Z.; Chen, X.; Lan, Y. One-Pot Synthesis of Core-Shell Cu@ $\mathrm{SiO}_{2}$ Nanospheres and Their Catalysis for Hydrolytic Dehydrogenation of Ammonia Borane and Hydrazine Borane. Sci. Rep. 2014, 4, 7597.

(18) Dinç, M.; Metin, Ö.; Özkar, S. Water Soluble Polymer Stabilized Iron(0) Nanoclusters: A CostEffective and Magnetically Recoverable Catalyst in Hydrogen Generation from the Hydrolysis of Sodium Borohydride and Ammonia Borane. Catal. Today 2012, 183, 10-16. 


\section{Supporting Information}

(19) Wang, H. X.; Zhao, Y. R.; Cheng, F. Y.; Tao, Z. L.; Chen, J. Cobalt Nanoparticles Embedded in Porous N-Doped Carbon as Long-Life Catalysts for Hydrolysis of Ammonia Borane. Catal. Sci. Technol. 2016, 6, 3443-3448.

(20) Hu, L.; Zheng, B.; Lai, Z.; Huang, K.-W. Room Temperature Hydrogen Generation from Hydrolysis of Ammonia-Borane over an Efficient NiAgPd/C Catalyst. Int. J. Hydrogen Energy 2014, 39, 20031-20037. (21) Çiftci, N. S.; Metin, Ö. Monodisperse Nickel-Palladium Alloy Nanoparticles Supported on Reduced Graphene Oxide as Highly Efficient Catalysts for the Hydrolytic Dehydrogenation of Ammonia Borane. Int. J. Hydrogen Energy 2014, 39, 18863-18870.

(22) Gungormez, K.; Metin, O. Composition-Controlled Catalysis of Reduced Graphene Oxide Supported CuPd Alloy Nanoparticles in the Hydrolytic Dehydrogenation of Ammonia Borane. Appl. Catal. A Gen. 2015, 494, 22-28.

(23) Liu, H.; Cao, C. Y.; Li, P.; Yu, Y.; Song, W. G. Core-Shell Structured Nanospheres with Mesoporous Silica Shell and Ni Core as a Stable Catalyst for Hydrolytic Dehydrogenation of Ammonia Borane. $J$. Energy Chem. 2014, 23, 50-56.

(24) Li, P. Z.; Aranishi, K.; Xu, Q. ZIF-8 Immobilized Nickel Nanoparticles: Highly Effective Catalysts for Hydrogen Generation from Hydrolysis of Ammonia Borane. Chem. Commun. 2012, 48, 3173-3175.

(25) Yang, L.; Cao, N.; Du, C.; Dai, H. M.; Hu, K.; Luo, W.; Cheng, G. Z. Graphene Supported Cobalt(0) Nanoparticles for Hydrolysis of Ammonia Borane. Mater. Lett. 2014, 115, 113-116.

(26) Tonbul, Y.; Akbayrak, S.; Ozkar, S. Palladium(0) Nanoparticles Supported on Ceria: Highly Active and Reusable Catalyst in Hydrogen Generation from the Hydrolysis of Ammonia Borane. Int. J. Hydrogen Energy 2016, 41, 11154-11162.

(27) Abo-Hamed, E. K.; Pennycook, T.; Vaynzof, Y.; Toprakcioglu, C.; Koutsioubas, A.; Scherman, O. A. Highly Active Metastable Ruthenium Nanoparticles for Hydrogen Production through the Catalytic Hydrolysis of Ammonia Borane. Small 2014, 10, 3145-3152.

(28) Yang, L.; Luo, W.; Cheng, G. Graphene-Supported Ag-Based Core-Shell Nanoparticles for Hydrogen Generation in Hydrolysis of Ammonia Borane and Methylamine Borane. ACS Applied Materials \& Interfaces 2013, 5, 8231-8240.

(29) Yan, J. M.; Wang, Z. L.; Wang, H. L.; Jiang, Q. Rapid and Energy-Efficient Synthesis of a GrapheneCuCo Hybrid as a High Performance Catalyst. J. Mater. Chem. 2012, 22, 10990-10993.

(30) Qi, X.; Li, X.; Chen, B.; Lu, H.; Wang, L.; He, G. Highly Active Nanoreactors: Patchlike or Thick Ni Coating on Pt Nanoparticles Based on Confined Catalysis. ACS Appl. Mater. Interfaces 2016, 8, 1922-1928.

(31) Feng, W. Q.; Yang, L.; Cao, N.; Du, C.; Dai, H. M.; Luo, W.; Cheng, G. Z. In Situ Facile Synthesis of Bimetallic CoNi Catalyst Supported on Graphene for Hydrolytic Dehydrogenation of Amine Borane. Int. J. Hydrogen Energy 2014, 39, 3371-3380.

(32) Yan, J. M.; Zhang, X. B.; Akita, T.; Haruta, M.; Xu, Q. One-Step Seeding Growth of Magnetically RecyclableAu@Co Core-Shell Nanoparticles: Highly Efficient Catalyst for Hydrolytic Dehydrogenation of Ammonia Borane. J. Am. Chem. Soc. 2010, 132, 5326-5327.

(33) Li, Y.; Dai, Y.; Tian, X.-k. Controlled Synthesis of Monodisperse $\mathrm{Pd}_{\mathrm{x}} \mathrm{Sn}_{100-\mathrm{x}}$ Nanoparticles and Their Catalytic Activity for Hydrogen Generation from the Hydrolysis of Ammonia-Borane. Int. J. Hydrogen Energy 2015, 40, 9235-9243.

(34) Yang, Y.; Zhang, F.; Wang, H.; Yao, Q.; Chen, X.; Lu, Z.-H. Catalytic Hydrolysis of Ammonia Borane by Cobalt Nickel Nanoparticles Supported on Reduced Graphene Oxide for Hydrogen Generation. $J$. Nanomater. 2014, 2014, 294350.

(35) Li, J.; Zhu, Q.-L.; Xu, Q. Non-Noble Bimetallic CuCo Nanoparticles Encapsulated in the Pores of Metal-Organic Frameworks: Synergetic Catalysis in the Hydrolysis of Ammonia Borane for Hydrogen Generation. Catal. Sci. Technol. 2015, 5, 525-530.

(36) Li, J.; Zhu, Q. L.; Xu, Q. Highly Active AuCo Alloy Nanoparticles Encapsulated in the Pores of MetalOrganic Frameworks for Hydrolytic Dehydrogenation of Ammonia Borane. Chem. Commun. 2014, 50, 5899-5901. 